\title{
The impact of hypertension on executive functions \& speed of processing in geriatric subjects
}

\author{
Jayamala A. K. ${ }^{1, *}$, Latha R. ${ }^{2}$, Nirmala N. ${ }^{3}$, Keerthika G. ${ }^{4}$, Saarumathi E. ${ }^{5}$ \\ ${ }^{1}$ Assistant Professor, ${ }^{2,3}$ Professor, Dept. of Physiology ${ }^{4,5}$ Student, MBBS Student, Sri Venkateshwaraa Medical College Hospital \\ $\&$ Research Centre, Pondicherry, India
}

*Corresponding Author:

Email: drjayamala2013@gmail.com

Received: $05^{\text {th }}$ February, 2018

Accepted: $23^{\text {rd }}$ February, 2018

\begin{abstract}
Introduction: Hypertension is a major contributor to cerebrovascular pathology causing dementia. Visual reaction time gives a better index of the cortical processing of Visual Stimulus. Trail Making Test provides information on visual search, scanning, speed of processing, mental flexibility, and executive functions. Our objective was to compare simple and choice reaction time (SRT \& CRT) and trail making scores between hypertensives and normotensives geriatric male subjects.

Materials and Methods: The present cross-sectional study was conducted on 60 Male hypertensives and normotensives aged $>60$ years, with BP $<140 / 90 \mathrm{~mm} \mathrm{Hg}$ were taken as controls \& BP $>140 / 90 \mathrm{~mm} \mathrm{Hg}$ were considered as hypertensive's. Computer programme recorded both SRT \& CRT using Deary- Liewald Reation Time Tester version 3.10. Trail making test was used as executive function test.

Results: Data were analysed using SPSS version- 20, Unpaired t-test showed significant difference in the reaction time scores of normotensives (SRT: M: 366.4 SD: 16.41; CRT: M: 737.6 SD:59.82 ) and hypertensives (SRT: M: 471.4 SD: 21.52 ; CRT: M: 902.4 SD: 55.57). In addition, the executive function showed significant difference between the executive ability of normotensives (TMT-B: M: 97.6, SD: 18.24) and hypertensives (TMT-B: M: 112.24 SD: 20.12).

Interpretation and Conclusion: The results showed that the hypertensive elderly males have a lower cognitive performance in comparison to age matched normotensives. Hypertension delays the speed of processing of information in elderly hence they are at higher risk for injuries and its consequences.
\end{abstract}

Keywords: Aged, Executive functions, Hypertension, Reaction Time, Trail making test.

\section{Introduction}

According to population census 2011 in India there are 104 million elderly persons. There is a rapid rise in the number of elderly in India and population aging is coupled with an increase in the incidence of cognitive impairment. ${ }^{1}$ It is a well known fact that cognitive impairment in older adults determines the quality of life of aged population. Research now targets to identify the probable causes and measures to prevent or delay cognitive decline as a more beneficial approach. ${ }^{2}$ Hypertension causes over 7.6 million premature deaths annually. ${ }^{3}$ Notably, older adults account for the bulk of hypertension-related morbidity and mortality - due to greater prevalence among the elderly. ${ }^{4}$ Hypertension is a major contributor to cerebrovascular pathology causing dementia. ${ }^{5}$ Changes in central nervous system due to hypertension are progressive and irreversible. The hypertension associated decline in cognitive performance will act together with age related decline in cognition. Cognitive aspect, Executive function measure was associated with differential decline older adults with high BP. ${ }^{6}$ A 6 year follow up study found that elders with high uncontrolled BP exhibited a greater degree of decline on a test of perceptual speed than normotensives. $^{7}$
In a Canadian Study of Health and Aging, a nationwide, population-based study in adults aged $>65$

they found no relationship of hypertension to cognitive function in non-demented persons. ${ }^{8}$ Speed of processing capability of central nervous system is indirectly assessed by Reaction time with well established diagnostic validity. ${ }^{9}$ Trail making test (TMT) measures sequencing and planning. The TMT-A score reflects visual search ability and motor skills, whereas TMT- B score additionally reflects the ability for cognitive alteration, thus, the time for completion of TMT-B is usually used as an index of executive function. ${ }^{10}$

Hence, the present study was planned to know the impact of hypertension on speed of processing and executive measure of cognition in older adults in Indian set-up. Therefore, the main objective of our study was to assess the cognitive function in hypertensive and normotensive older adult population.

\section{Materials and Methods}

A cross sectional study was carried out among 60 elderly males aged >60years from April 2016 to July 2017 in Sri Venkateshwaraa Medical College Hospital $\&$ Research Centre after obtaining Institutional Ethics Committee clearance before the commencement of the study. The subjects were explained the testing 
procedure and protocol. Informed consent was taken from study participants. Medical history was taken and general examination of all the participants was done.

Eligibility criteria for study participants was age equal to or more than 60 years, \& 6/18 minimum far visual acuity (with use of corrective lenses if needed), and a tenth grade education level. 30 Males aged $>60$ years, who are known case of hypertension or if their blood pressure was more than 140/90 on the day of measurement were included as cases and 30 subjects with BP $<140 / 90$ were included as controls. ${ }^{11}$

Anthropometric measurements: A digital weighing scale was used to record weight, and height was measured using a stadiometer, in the Frankfurt plane position.

Assessment of Body Mass Index (BMI): BMI was calculated by dividing the weight in $\mathrm{Kg}$ by the square of the height in meters. ${ }^{12}$

Recording of Blood pressure: Following the AHA guidelines. ${ }^{13}$ blood pressure was measured in all the individuals in sitting posture using a manual sphygmomanometer.

Two readings were taken at an interval of five minute and the average of the two readings was taken as the blood pressure of the subject.

Recording of Visual Reaction Time (VRT) SRT \& CRT: The Visual Reaction Time (VRT) test was done using a computer programme Deary-Liewald reaction time tester (DLRT) version 3.10 released in 2010 by Department of Psychology, University of Edinburgh, UK. ${ }^{14}$

In the Simple Reaction Time (SRT), participants had to press a button in response to a single stimulus. To record SRT, 8 practice trials and 20 test trials were given. For the SRT, in the centre of a computer screen, single white square with blue background was shown. Every time a cross appeared in the white square, subject had to press a key as quickly as possible. Each cross remained on the screen till the key was pressed, after pressing key it disappeared and another cross appeared shortly later. The inter-stimulus interval (the time interval between each response and when the next cross appeared) ranged between 1 and $3 \mathrm{~s}$ and was randomised within these boundaries. The interstimulus interval for each trial was recorded by computer programme.

In the Choice Reaction Time (CRT), four stimuli were shown randomly and subjects was asked to press the button that corresponded to the accurate response. The CRT tasks included 8 practice trials and 40 test trials. For the CRT, on the computer screen 4 white squares with blue background were placed in a horizontal line. Four keys on a standard computer keyboard corresponded to the different squares. The position of the keys corresponded in alignment to the position of the squares on the screen: the ' $z$ ' key correspond to the square on the far left, the ' $x$ ' key to the square second from the left, the 'comma' key to the square second from the left, the 'comma' key to the square second from the right and the 'full-stop' key to the square on the far right.

The subject had to respond when a diagonal cross appeared in one of the squares. Participants were asked to rest the index and middle fingers of their left hand on the ' $z$ ' and the ' $x$ ' keys, and the index and middle fingers of their right hand on the 'comma' and 'full stop' keys. When a cross appeared randomly in any one of the squares, subjects were asked to respond as quickly as possible by pressing the corresponding key on the keyboard. Each stimulus remained on the screen until subject presses one of the four keys, after which it disappeared and another cross appeared shortly after. The interval between two stimuli ranged between 1 and $3 \mathrm{~s}$ and was randomised within these boundaries. The inter stimulus interval for each trial was recorded by computer programme. In CRT, whether the response was correct or incorrect was also recorded by computer software. Mean and standard deviation was measured for each participant.

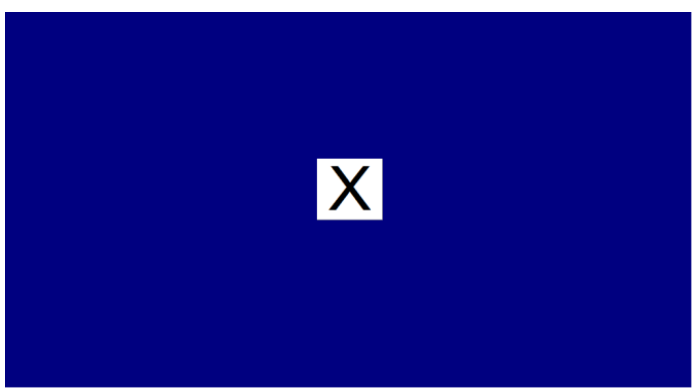

Fig. 1: Simple Reaction Time Task



Fig. 2: Choice Reaction Time task

\section{Recording of Trail Making Test:}

The TMT consists of two parts ${ }^{15}$. In TMT-A subject has to draw lines connecting 25 encircled numbers sequentially which are randomly distributed on a sheet of paper as fast as possible. Likewise in TMT-B, the subject had to connect numbers and letters alternatively (e.g., 1, A, 2, B, 3, C, ) and it evaluates mental flexibility. The score on each part represents the amount of time required to complete the task. Time was limited to $480 \mathrm{~s}$ in this study ${ }^{16}$. Trail making test B-A score is considered as a better indicator of executive functions. 
Variables studied:

1. Anthropometric variables-height, weight

2. BMI

3. Cardiovascular $(\mathrm{CV})$ parameters $-\mathrm{SBP}, \mathrm{DBP}$

4. Visual Reaction Time- SRT, CRT

5. Trail making test - A score, B score, B minus A score (B-A)

\section{Statistical analysis}

The data were expressed as mean $\pm \mathrm{SD}$. The statistical analysis was done with Statistical Package for Social Sciences version 20 manufactured by SPSS Inc. (Chicago). Unpaired t- test was used to find the difference between 2 groups. $\mathrm{P}<0.05$ was considered to be statistically significant.

\section{Results}

The anthropometrics details of the participating subjects are given in table 1 . The mean age of the healthy control $(61 \pm 1.84)$ was slightly less than that of the hypertension group $(64.5 \pm 6.09)$.

\begin{tabular}{|c|c|c|}
\hline Parameters & $\begin{array}{l}\text { Normal BP } \\
(\text { mean } \pm \text { SD) }\end{array}$ & $\begin{array}{l}\text { Hypertension } \\
(\text { mean } \pm \text { SD) }\end{array}$ \\
\hline Age (Years) & $61 \pm 1.84$ & $64.5 \pm 6.09$ \\
\hline $\mathrm{BMI}\left(\mathrm{kg} / \mathrm{m}^{2}\right)$ & $26 \pm 4$ & $27 \pm 4$ \\
\hline $\mathrm{SBP}(\mathrm{mmHg})$ & $126 \pm 14$ & $158 \pm 12$ \\
\hline $\mathrm{DBP}(\mathrm{mmHg})$ & $72 \pm 6$ & $96 \pm 12$ \\
\hline \multicolumn{3}{|c|}{$\begin{array}{l}\text { Data is expressed as mean } \pm \text { SD. SBP (Systolic } \\
\text { Blood Pressure); DBP (Diastolic Blood } \\
\text { Pressure). Statistical analysis was done by } \\
\text { two tailed unpaired } t \text { - test. P-value }<0.05 \text { was } \\
\text { considered significant. }\end{array}$} \\
\hline
\end{tabular}

Table 2: visual reaction time in subjects stratified by blood pressure

\begin{tabular}{|c|c|c|c|}
\hline Parameters & $\begin{array}{c}\text { Normal BP } \\
\left(\begin{array}{c}\text { mean } \pm \text { SD }) \\
n=24\end{array}\right.\end{array}$ & $\begin{array}{c}\text { Hypertension } \\
\left(\begin{array}{c}\text { mean } \pm \text { SD) } \\
\mathbf{n}=\mathbf{2 8}\end{array}\right.\end{array}$ & $\begin{array}{c}\text { p- } \\
\text { value }\end{array}$ \\
\hline SRT & $366.4 \pm 16.41$ & $471.4 \pm 21.52$ & 0.006 \\
\hline CRT & 9.82 & 902 & 0.053 \\
\hline Errors ir & 50 & & 0.2472 \\
\hline Errors & & 9.14 & 0.010 \\
\hline TMT- A & 2.21 & .24 & 0.1319 \\
\hline TMT- B & 18.24 & 20.12 & 0.0045 \\
\hline TMT B-A & $49.28 \pm 6.03$ & $56.81 \pm 11.88$ & 0.0030 \\
\hline \multicolumn{4}{|c|}{$\begin{array}{l}\text { Data is expressed as mean } \pm \text { SD. SRT (Simple reaction time); } \\
\text { CRT (Choice reaction time). Statistical analysis was done by } \\
\text { two tailed unpaired t - test. P-value }<0.05 \text { was considered } \\
\text { significant. }\end{array}$} \\
\hline
\end{tabular}

\section{Discussion}

In this study we analysed the reaction time among a sample of hypertensive and normotensive older adults while taking into account about other factors that may impact cognition. Our results showed a significant difference in visual reaction time among subjects with and without hypertension. SRT \& CRT points out general alertness and motor speed. In this study both simple \& choice reaction time was significantly slower in hypertensives than normotensives.

Error in choice reaction time was more in hypertensives compared to normotensives. When multiple choices were given for the subjects the number of error were more. In this study, 4 choices were given to subjects the mean error by hypertensives is $9.14 \pm 0.88$ compared to normotensives $6 \pm 0.53$ which is a significant difference.

This results support the hypothesis that High blood pressure is associated with reduced cognitive performance. ${ }^{17-19}$ Study done by Elizabeth $\mathrm{M}$ et al, 2013 on 770 subjects demonstrated slower processing speed, reaction time, motor speed and IADL (Instrumental activity of daily living) performance among hypertensives with \& without treatment. ${ }^{11}$ Our results are in consistent with the above studies.

Recent evidence suggests that hypertension itself has a direct negative effect on cerebral auto-regulatory mechanism. Hypertension and aging leads to brain atrophy especially in regions like prefrontal cortex and hippocampus which are concerned with memory. ${ }^{20}$ One of the manifestations of cerebral small vessel diseases is white matter hyperintensities (WMH) on MRI scans. Hypertension is associated with WMH progression ${ }^{21}$ especially in frontal lobe. ${ }^{22} \mathrm{WMH}$ is linked to cognitive decline, dementia, stroke \& death. Hypertension reduces cognitive ability which in turn leads to slower reaction time. ${ }^{23}$

Among the mental abilities, processing speed and central executive functions are especially critical in everyday functioning. The prospect of examining the 
reaction time association with hypertension and normal aging contributes to a better understanding of the executive control process and of the aging process. Executive function task helps in predicting functional decline $^{24} \&$ detecting persons at risk for alzehiemers disease. ${ }^{25}$ Even in educated older adults, executive control functions are critical for successful \& independent functioning and in activities such as medical compliance. ${ }^{26}$ Older adults are more prone for fall, in such a incident avoiding a fall requires perception of postural threat, selection of an appropriate corrective measure $\&$ proper response execution. ${ }^{27}$ There is a age related increase in movement time and decision making time in case of fall. ${ }^{28,29}$ Increase in SRT is an independent risk factor for fall in elderly. ${ }^{30-32}$ As shown in this study in hypertensive patients since cognitive decline is more they are at very high risk for fall in elderly.

Older drivers have more crash and fatality rates. Individuals with cognitive impairment are more likely to be involved in an at-fault crash $^{33}$ Chronological age \& visual acuity alone is usually considered in individuals for issuing driving license. Reaction time which indicates how fast they can respond to any problems needs to assess before issuing licence. The successful utilization of technology is becoming increasingly important for functional independence. Few studies have shown that cognitive abilities like speed of processing and memory are important to successfully perform technology based tasks. Due to declining cognitive ability older adults are at disadvantage in terms of their ability to live \& function independently \& successfully perform everyday tasks. ${ }^{34}$

\section{Conclusion}

Ours is a cross sectional study consisting of 60 geriatric male participants with and without hypertension. 2 tasks VRT and TMT were performed by the subjects which are a indirect indicator of executive functions \& speed of processing. The results show that there was statistically significant difference between two groups. Hypertensive elderly male subjects had slower speed of processing and executive functions compared to normotensive subjects.

\section{References}

1. Elderly in India- profile and programmes 2016. Central statistics office, ministry of statistics and program implementation, Government of India.

2. Zielińska $\mathrm{MA}^{1}$, Białecka $\mathrm{A}^{1}$, Pietruszka $\mathrm{B}^{1}$, Hamułka $\mathrm{J}^{1}$, Vegetables and fruit, as a source of bioactive substances, and impact on memory and cognitive function of elderly. Postepy Hig Med Dosw (Online). 2017 Apr 12;71(0):267-80.

3. Go AS, Mozaffarian D, Roger VL, Benjamin EJ, Berry JD, Blaha MJ, et al. Heart disease and stroke statistics2014 update. A report from the American Heart Assosciation. Circulation 204;129: e 28-92.
4. Mozaffarian D, Benjamin EJ, Go AS, Arnett DK, Blaha MJ, Cushman M, et al. American Heart Association Statistics Committee and Stroke Statistics Subcommittee. Heart disease and stroke statistics-2015 update: a report from the American Heart Association. Circulation. 2015; 131:e29-322. [PubMed: 25520374]

5. Raz, L., Knoefel, J., \& Bhaskar, K. (2016). The neuropathology and cerebrovascular mechanisms of dementia. Journal of Cerebral Blood Flow \& Metabolism, 36(1),172-86.

6. Bucur $\mathrm{B}^{1}$, Madden DJ. Effects of adult age and blood pressure on executive function and speed of processing. Exp Aging Res. 2010 Apr;36(2):153-68.

7. Alves De Moraes S, Szklo M, Knopman D, Sato R. The relationship between temporal changes in blood pressure and changes in cognitive function: Atherosclerosis Risk In Communities (ARIC) study. Preventive medicine 2002;35:258-63.

8. Lindsay J, Laurin D, Verreault R, et al. Risk factors for Alzheimer's disease: a prospective analysis from the Canadian study of health and aging. Am J Epidemiol. 2002;156:445-53.

9. Madiha Mehvish, Anupriya Deshpande, A comparative study of hand dominance and assessment of cognitive function by reaction time in non-smokers and chronic smokers. Journal of Evolution of Research in Human Physiology, 2016;2:18-20.

10. Crowse SF. The differential contribution of mental tracking, cognitive flexibility, visual search, and motor speed to performance on parts A and B of the trail making test. J. Clin. Psychol. 1998;54:585-91.

11. Elizabeth M H, Jerri D E, Ponrathi A, Cathy L M. A comparison of cognitive and everyday functional performance among older adults with and without hypertension. Clin Gerontol. 2013;36(2):113-31.

12. Sood AK, Kapil U. Utility of nutritional indices derived from body weight and height: a comparative study. Indian Pediatr 1991;28:65-7.

13. Pickering TG, Hall JE, Appel LJ, Falkner BE, Graves J, Hill MN, et al. Recommendations for blood pressure measurement in humans and experimental animals: part 1: blood pressure measurement in humans: a statement for professionals from the Subcommittee of Professional and Public Education of the American Heart Association Council on High Blood Pressure Research. Circulation 2005;111:697-716.

14. Deary JI, Liewald D, Nissan J. A free, easy to use, computer based simple and four - choice reaction time programme: The Deary - Liewald reaction time task. Behav Res. 2011;43:258-68.

15. Reitan, R. M., \& Wolfson, D. (1985). The HalsteadReitan Neuropsycholgical Test Battery: Therapy and clinical interpretation. Tucson, AZ: Neuropsychological Press.

16. Wood KM, Edwards JD, Clay OJ, Wadley VG, Roenker DL, Ball KK. Sensory and cognitive factors influencing functional ability in older adults. Gerontology. 2005;51:131-41.

17. Obisesan TO, Obisesan OA, Martins S, et al. High blood pressure, hypertension, and high pulse pressure are associated with poorer cognitive function in persons aged 60 and older: the Third National Health and Nutrition Examination Survey. J Am Geriatr Soc. 2008;56:501-9. [PubMed: 18179496]

18. Melinda C, Eric J, David S, et al. Blood pressure and cognition: Factors that may account for their inconsistent association. Epidemiology. 2013;Nov24(6). 
19. Brady C B, Spiro A, Gaziano. Effects of age and hypertension status on cognition: The veteran affairs normative aging study. Neuropsychology, 19(6):770-7.

20. Gasecki D, Kwarciany M, Nyka W, Narkiewicz K. Hypertension, brain damage \& cognitive decline. Curr Hypertens Rep 2013;15:547-58.

21. Verhaaren BF, Vernooij MW, de Boer R, Hofman A, Niessen WJ, van der Lugt A, et al. High blood pressure and cerebral white matter lesion progression in the general population. Hypertension.2013;61(6):1354-9.

22. Raz N, Yang YQ, Rodrigue KM, Kennedy KM, Lindenberger U, Ghisletta P. White matter deterioration in 15 months: latent growth curve models in healthy adults. Neurobiol Aging. 2012; 33(2):429.e1-5.

23. Debette S, Markus HS. The clinical importance of white matter hyperintensities on brain magnetic resonance imaging: systematic review and meta-analysis. BMJ. 2010;341: c3666.

24. Johnson JK, Lui LY, Yaffe K. Executive function, more than global cognition, predicts functional decline and mortality in elderly women. J Gerontol A Bio Sci Med Sci. 2007; 62(10):1134-41.

25. Wetter SR, Delis DC, Houston WS, et al. Deficits in inhibition and flexibility are associated with APOE-E4 allele in nondemented older adults. J Clin Exp Neuropsychol. 2005;27(8):943:52.

26. Carlson MC, Fried LP, Xue QL, et al. Validation of the Hopkins Medication schedule to identify difficulties in taking medications. J Gerontol A Bio Sci Med Sci. 2005;60(2):217-23.

27. Stelmach GE, Worringham CJ, 1985. Sensorimotor deficits related to postural stability: implications for falling in the elderly. Clin Geriatr Med.1:679-94.

28. Onishi N, 1966. Changes of the jumping reaction time in relation to age. J Sci Lab.42:5-16.

29. Spurduso WW, 1975. Reaction and movement time as a function of age and physical activity level. J Gerontol.30: 435-40.

30. Lord SR, Clark RD, Webster IW,1991. Physiological factors associated with falls in an elderly population. $J$ Am Geriatr Soc. 39:1194-200.

31. Lord SR, Ward JA, Williams P, Anstey K, 1994. Physiological factors associated with falls in older community-dwelling women. J Am Geriatr Soc.42:11107.

32. Lord SR, Clark RD, 1996. Simple physiological and clinical tests for the accurate prediction of falling in older people. Gerontology.42:199-203.

33. Diller E, Cook L, Leonard D, et al. DOT HS 809023 Washington, DC: National Highway Traffic Safety Administration; 1999. Evaluating drivers licensed with medical conditions in Utah, 1992-6.

34. Czaja SJ, Charness N, Fisk AD, et al. Factors predicting the use of technology: Findings from the Centre for Research on Aging and Technology Enhancement (CREATE) Psychology and Aging. 2006;21:333-5. 